\begin{tabular}{|c|c|c|}
\hline \multirow{3}{*}{$\begin{array}{r}\text { Case Reports in } \\
\text { Gastroenterology }\end{array}$} & \multirow{2}{*}{\multicolumn{2}{|c|}{ Case Rep Gastroenterol 2014;8:32-38 }} \\
\hline & & \\
\hline & $\begin{array}{l}\text { DOI: } 10.1159 / 000358553 \\
\text { Published online: January 23, } 2014\end{array}$ & $\begin{array}{l}\text { ○ } 2014 \text { S. Karger AG, Basel } \\
\text { 1662-0631/14/0081-0032 } \$ 39.50 / 0 \\
\text { www.karger.com/crg }\end{array}$ \\
\hline & \multicolumn{2}{|c|}{$\begin{array}{l}\text { This is an Open Access article licensed under the terms of the Creative Commons } \\
\text { Attribution-NonCommercial } 3.0 \text { Unported license (CC BY-NC) (www.karger.com/OA } \\
\text { license), applicable to the online version of the article only. Distribution permitted for non } \\
\text { commercial purposes only. }\end{array}$} \\
\hline
\end{tabular}

\title{
Recurrent Upside-Down Stomach after Endoscopic Repositioning and Gastropexy Treated by Laparoscopic Surgery
}

\author{
Kazuhiro Toyota ${ }^{a}$ Yuji Sugawara ${ }^{a}$ Yu Hatano $^{b}$ \\ Departments of ${ }^{a}$ Surgery and ${ }^{b}$ Internal Medicine, Mitsugi General Hospital, Mitsugi, Japan
}

\section{Key Words}

Upside-down stomach · Endoscopic therapy · Laparoscopic surgery

\begin{abstract}
Patients with an upside-down stomach usually receive surgical treatment. In high-risk patients, endoscopic repositioning and gastropexy can be performed. However, the risk of recurrence after endoscopic treatment is not known. We treated a case of recurrent upsidedown stomach after endoscopic therapy that indicated the limits of endoscopic treatment and risk of recurrence. An 88-year-old woman was treated three times for vomiting in the past. She presented to our hospital with periodic vomiting and an inability to eat, and a diagnosis of upside-down stomach was made. Endoscopic repositioning and gastropexy were performed. The anterior stomach wall was fixed to the abdominal wall in three places as widely as possible. Following treatment, she became symptom-free. Three months later, she was hospitalized again because of a recurrent upside-down stomach. Laparoscopic repair of hernias and gastropexy was performed. Using a laparoscope, two causes of recurrence were found. One cause was that the range of adherence between the stomach and the abdominal wall was narrow (from the antrum only to the lower corpus of stomach), so the upper corpus of stomach was rotated and herniated into the esophageal hiatus. The other cause was adhesion between the omentum and the esophageal hiatus which caused the stomach to rotate and repeatedly become herniated. Although endoscopic treatment for upside-down stomach can be a useful alternative method in high-risk patients, its ability to prevent recurrence is limited. Moreover, a repeated case caused by adhesions has risks of recurrence.
\end{abstract}


Toyota et al.: Recurrent Upside-Down Stomach after Endoscopic Repositioning and Gastropexy Treated by Laparoscopic Surgery

\section{Introduction}

In cases of paraesophageal hiatal hernia with gastric volvulus, which is referred to as upside-down stomach, the first choice is surgical treatment. In high-surgical-risk patients, endoscopic repositioning and gastropexy is useful to ensure a good quality of life. However, there are no detailed reports regarding recurrent cases of upside-down stomach after endoscopic treatment; therefore, the risks of recurrence are unknown. We had a case of recurrent upside-down stomach after endoscopic repositioning and gastropexy that indicated the limits of endoscopic treatment and the risk of recurrence, as reported here.

\section{Case Report}

An 88-year-old woman with periodic vomiting and inability to eat was admitted to our hospital on three separate occasions where she received conservative treatment for a few days. Upside-down stomach was diagnosed. Because of her advanced age, complications (bedridden state, left hemiplegia after cerebral infarction, heart failure) and poor general condition, the minimally invasive method of endoscopic repositioning and gastropexy was performed. The stomach was reduced to the normal anatomic position, and the anterior stomach wall was fixed to the abdominal wall in three places as widely as possible (fig. 1). She became symptom-free and was discharged on postoperative day 12 .

Three months later, she was hospitalized again because of vomiting. Chest and abdominal computed tomography showed the gastric fornix in the abdominal cavity, but the gastric corpus was above the diaphragm with organoaxial volvulus (fig. 2). She was then diagnosed with a recurrent upside-down stomach after endoscopic repositioning and gastropexy. She was initially managed conservatively and had a nasogastric tube inserted, but her condition did not improve.

Although her anterior stomach wall had been fixed to the abdominal wall in three places as widely as possible in the last hospitalization, she again presented with upside-down stomach. We concluded that it was impossible to prevent the recurrence of an upside-down stomach by endoscopic therapy. Therefore, we treated the condition with a laparoscopic repair of hernias and gastropexy.

Using a laparoscope, we observed that the anterior stomach wall was adhered to the abdominal wall in three places from the antrum to the lower corpus of the stomach (fig. 3a). The upper corpus of the stomach was rotated and herniated into the esophageal hiatus (fig. 3b). The herniated part of the stomach was repositioned easily. However, it quickly returned into the esophageal hiatus with rotation because of the adhesion between the omentum and the esophageal hiatus (fig. 3c). This adhesion was peeled off and the crura were closed by a primary suture (fig. $3 \mathrm{~d}$, e). The cardial part of the stomach wall was fixed to the crura, and the anterior stomach wall was fixed in three places to the abdominal wall widely from the upper corpus to the antrum (fig. 3f).

Oral ingestion was started the day after surgery. After rehabilitation, the patient was discharged 18 days after the operation. The suture used for fixing the stomach wall was removed 44 days after the operation. Three months after removal of the suture, the patient remained asymptomatic. 
Toyota et al.: Recurrent Upside-Down Stomach after Endoscopic Repositioning and Gastropexy Treated by Laparoscopic Surgery

\section{Discussion}

A paraesophageal hiatal hernia is a herniation of the gastric fundus anterior to a normally positioned esophagogastric junction [1]. In large paraesophageal hernias, the entire stomach can be herniated with volvulus, which we refer to as upside-down stomach. Surgical intervention comprising reduction of the stomach in the gastric lodge and calibration of the hiatus adding a gastropexy or antireflux procedure is the first choice of treatment for this condition.

The procedure for surgical repair of paraesophageal hiatal hernias is controversial and not standardized. Although publications describe the results of retrospective studies, the hospital stay after laparoscopic repair of paraesophageal hiatal hernias was shorter than that after conventional surgery [2]. The morbidity reported in patients treated by conventional surgery exceeded the morbidity reported in laparoscopically operated patients, and follow-up was longer for conventional surgery [2]. The recurrence rate after laparoscopic repair for large hiatal hernias was higher than after conventional repair [3]. Use of mesh decreased recurrence in comparison with a simple hiatal hernia repair [4]. Complications of mesh repair include dysphagia, heartburn and chest pain. Reoperative findings were intraluminal mesh erosion, esophageal stenosis, dense fibrosis, esophageal perforation and intragastric migration $[5,6]$. Considering the recurrence and reoperation rates, the differences between mesh repair and primary repair were small and perhaps clinically inconsequential [7]. In our case, the esophageal hiatus was not so large and could be closed easily; therefore, we did not use mesh. The addition of a fundoplication in the laparoscopic repair of paraesophageal hiatal hernia minimized postoperative reflux symptoms [8]. When no objective evidence of reflux was seen preoperatively, an antireflux procedure was not necessary [9]. In our case, gastroesophageal reflux was not seen by gastrointestinal endoscopy during the last endoscopic treatment. A fundoplication, therefore, was not performed and reflux symptoms were not observed following the procedure. For upside-down stomach, preventing recurrence of volvulus, a gastropexy is added to repair the paraesophageal hiatal hernia. In our case, the anterior stomach wall was fixed in three places to the abdominal wall widely from the upper corpus to the antrum.

Many patients with upside-down stomach are not candidates for surgical therapy because of advanced age or comorbid conditions. For these patients, endoscopic repositioning and fixation by percutaneous endoscopic gastrostomy (PEG) can be performed [10, 11]. In our case, the patient was of advanced age (88 years) and in poor condition. Endoscopic repositioning and gastropexy was therefore performed for the first time. Her upside-down stomach was relieved temporally, but recurred. Two reasons are postulated for this recurrence. One reason is the narrow range where the stomach wall can be fixed endoscopically, although the fixation was performed as widely as possible. Wide fixation of the stomach is important to prevent recurrences. Therefore, performing endoscopic gastropexy fixation of the stomach by 2 PEGs is recommended $[12,13]$. In our case, the anterior stomach wall was fixed to the abdominal wall in three places as widely as possible. However, as observed with a laparoscope, the anterior stomach wall was adhered only from the antrum to the lower corpus of the stomach, and the upper corpus of the stomach was rotated and herniated into the esophageal hiatus. In endoscopic gastropexy, the stomach wall is fixed by penetrating the PEG tube or stomach wall fixture through the stomach wall and the abdominal wall. To avoid penetrating the chest wall and the lungs, the range of abdominal wall which can be fixed to the stomach wall is limited from the epigastrium to the left hypochondrium. Since the stomach wall cannot be pulled caudally, unlike in the surgical approach, the range of 
Toyota et al.: Recurrent Upside-Down Stomach after Endoscopic Repositioning and Gastropexy Treated by Laparoscopic Surgery

stomach wall which can be fixed to the abdominal wall is limited from the antrum to the lower corpus of the stomach. As a result, the upper stomach may be rotated.

The other reason for recurrence is the adhesion between the omentum and the esophageal hiatus. Adhesions often account for the repeated case of upside-down stomach. However, adhesions cannot be improved by endoscopic treatment. Therefore, a repeated case has risks of recurrence of upside-down stomach after endoscopic treatment.

In conclusion, although endoscopic repositioning and gastropexy for upside-down stomach can be a useful alternative method in high-risk patients, some cases may recur. Repeated upside-down stomach caused by adhesions has risks of recurrence after endoscopic treatment. To use this therapy more effectively, we hope that more cases will be reported and the risks of recurrences revealed.

\section{Disclosure Statement}

No potential conflicts of interest relevant to this article are reported.

\section{References}

1 Hill LD, Tobias JA: Paraesophageal hernia. Arch Surg 1968;96:735-744.

$\checkmark 2$ Draaisma WA, Gooszen HG, Tournoij E, Broeders IA: Controversies in paraesophageal hernia repair: a review of literature. Surg Endosc 2005;19:1300-1308.

-3 Hashemi M, Peters JH, DeMeester TR, Huprich JE, Quek M, Hagen JA, Crookes PF, Theisen J, DeMeester SR, Sillin LF, Bremner CG: Laparoscopic repair of large type III hiatal hernia: objective followup reveals high recurrence rate. J Am Coll Surg 2000;190:553-560; discussion 560-561.

-4 Antoniou SA, Antoniou GA, Koch 00, Pointner R, Granderath FA: Lower recurrence rates after meshreinforced versus simple hiatal hernia repair: a meta-analysis of randomized trials. Surg Laparosc Endosc Percutan Tech 2012;22:498-502.

-5 Stadlhuber RJ, Sherif AE, Mittal SK, Fitzgibbons RJ Jr, Michael Brunt L, Hunter JG, Demeester TR, Swanstrom LL, Daniel Smith C, Filipi CJ: Mesh complication after prosthetic reinforcement of hiatal closure: a 28-case series. Surg Endosc 2009;23:1219-1226.

6 De Moor V, Zalcman M, Delhaye M, El Nakadi I: Complications of mesh repair in hiatal surgery: about 3 cases and review of the literature. Surg Laparosc Endosc Percutan Tech 2012;22:222-225.

7 Obeid NM, Velanovich V: The choice of primary repair or mesh repair for paraesophageal hernia: a decision analysis based on utility scores. Ann Surg 2013;257:655-664.

8 van der Westhuizen L, Dunphy KM, Knott B, Carbonell AM, Smith DE, Cobb WS 4th: The need for fundoplication at the time of laparoscopic paraesophageal hernia repair. Am Surg 2013;79:572-577.

-9 Williamson WA, Ellis FH Jr, Streitz JM Jr, Shahian DM: Paraesophageal hiatal hernia: is an antireflux procedure necessary? Ann Thorac Surg 1993;56:447-451.

10 Lukovich P, Dudás I, Tari K, Jónás A, Herczeg G: PEG fixation of an upside-down stomach using a flexible endoscope: case report and review of the literature. Surg Laparosc Endosc Percutan Tech 2013;23:65-69.

11 Tabo T, Hayashi H, Umeyama S, Yoshida M, Onodera H: Balloon repositioning of intrathoracic upside-down stomach and fixation by percutaneous endoscopic gastrostomy. J Am Coll Surg 2003;197:868-871.

12 Eckhauser ML, Ferron JP: The use of dual percutaneous endoscopic gastrostomy (DPEG) in the management of chronic intermittent gastric volvulus. Gastrointest Endosc 1985;31:340-342.

13 Ghosh S, Palmer KR: Double percutaneous endoscopic gastrostomy fixation: an effective treatment for recurrent gastric volvulus. Am J Gastroenterol 1993;88:1271-1272. 


\begin{tabular}{l|l}
\hline Case Rep Gastroenterol 2014;8:32-38 \\
\hline DOI: 10.1159/000358553 & $\begin{array}{l}\text { @ 2014 S. Karger AG, Basel } \\
\text { www.karger.com/crg }\end{array}$ \\
\hline
\end{tabular}

Toyota et al:: Recurrent Upside-Down Stomach after Endoscopic Repositioning and Gastropexy Treated by Laparoscopic Surgery
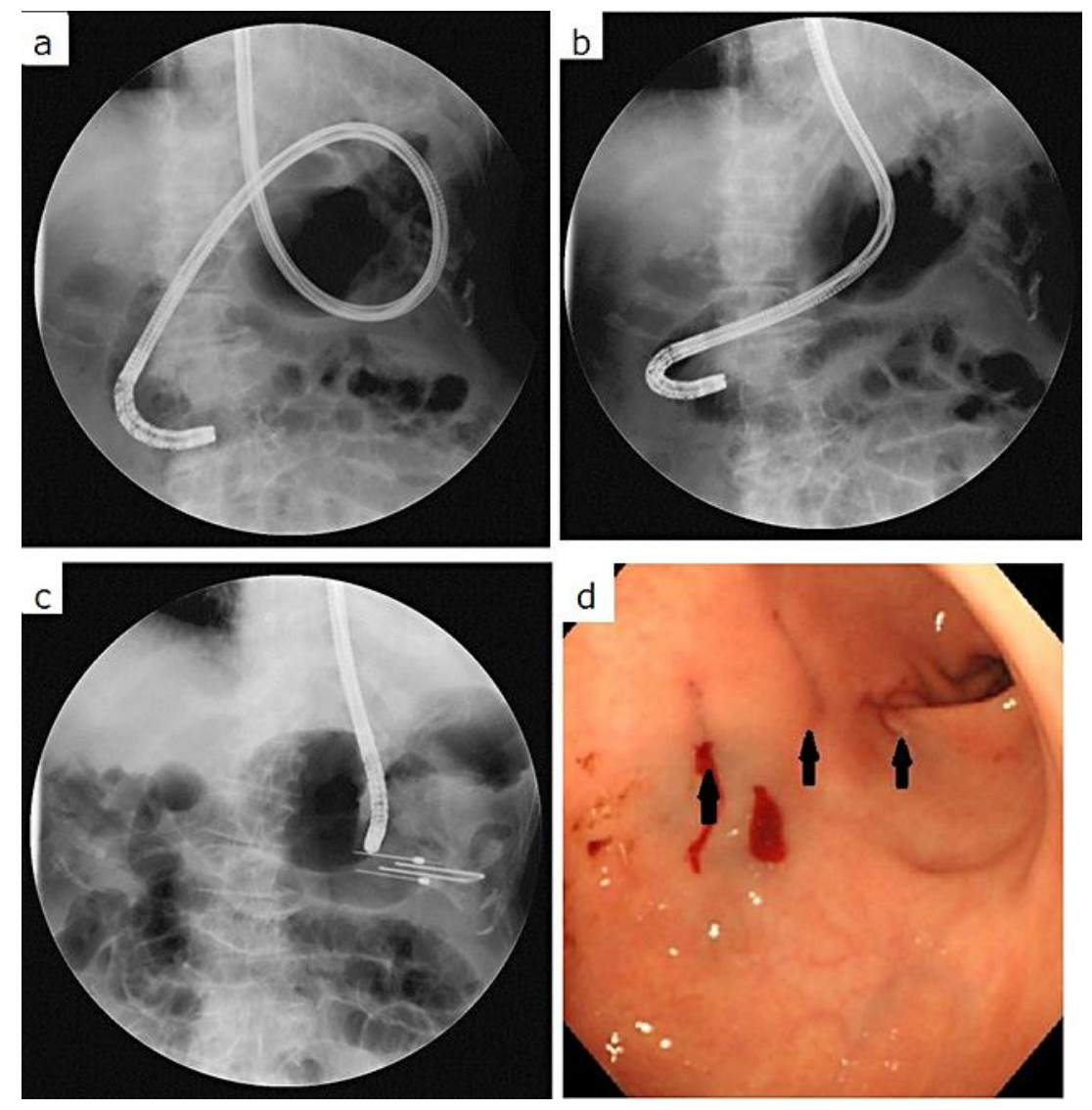

Fig. 1. a, b After inserting the gastroscope into the duodenum, the stomach was reduced to the normal anatomic position. $\mathbf{c}$ The anterior stomach wall was fixed to the abdominal wall by stomach wall fixture. d Endoscopic findings showed the stomach wall fixed in three places (arrows). 


\begin{tabular}{ll|l} 
Case Reports in & \multicolumn{2}{l}{} \\
\cline { 2 - 3 } Gastroenterology & Case Rep Gastroenterol 2014;8:32-38 & $\begin{array}{l}\text { C 2014 S. Karger AG, Basel } \\
\text { www.karger.com/crg }\end{array}$ \\
\cline { 2 - 3 } & DOI:1159/000358553 &
\end{tabular}

Toyota et al.: Recurrent Upside-Down Stomach after Endoscopic Repositioning and Gastropexy Treated by Laparoscopic Surgery

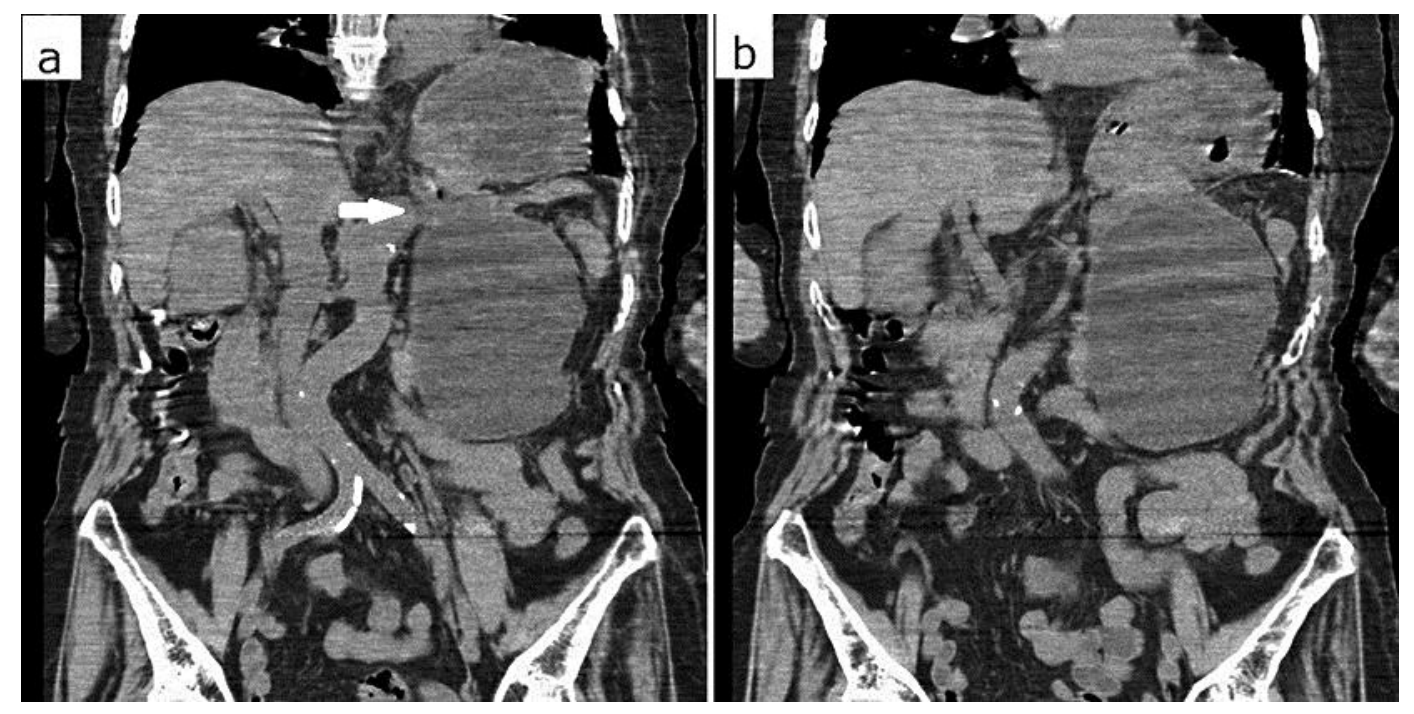

Fig. 2. Findings of chest and abdominal computed tomography. a The cardia (arrow) and the gastric fornix were present in the normal position, and the stomach was dilated significantly. $\mathbf{b}$ The gastric corpus was displayed above the diaphragm. 


\begin{tabular}{l|l}
\hline Case Rep Gastroenterol 2014;8:32-38 \\
\hline DOI: 10.1159/000358553 & $\begin{array}{l}\text { ○ 2014 S. Karger AG, Basel } \\
\text { www.karger.com/crg }\end{array}$ \\
\hline
\end{tabular}

Toyota et al.: Recurrent Upside-Down Stomach after Endoscopic Repositioning and Gastropexy Treated by Laparoscopic Surgery
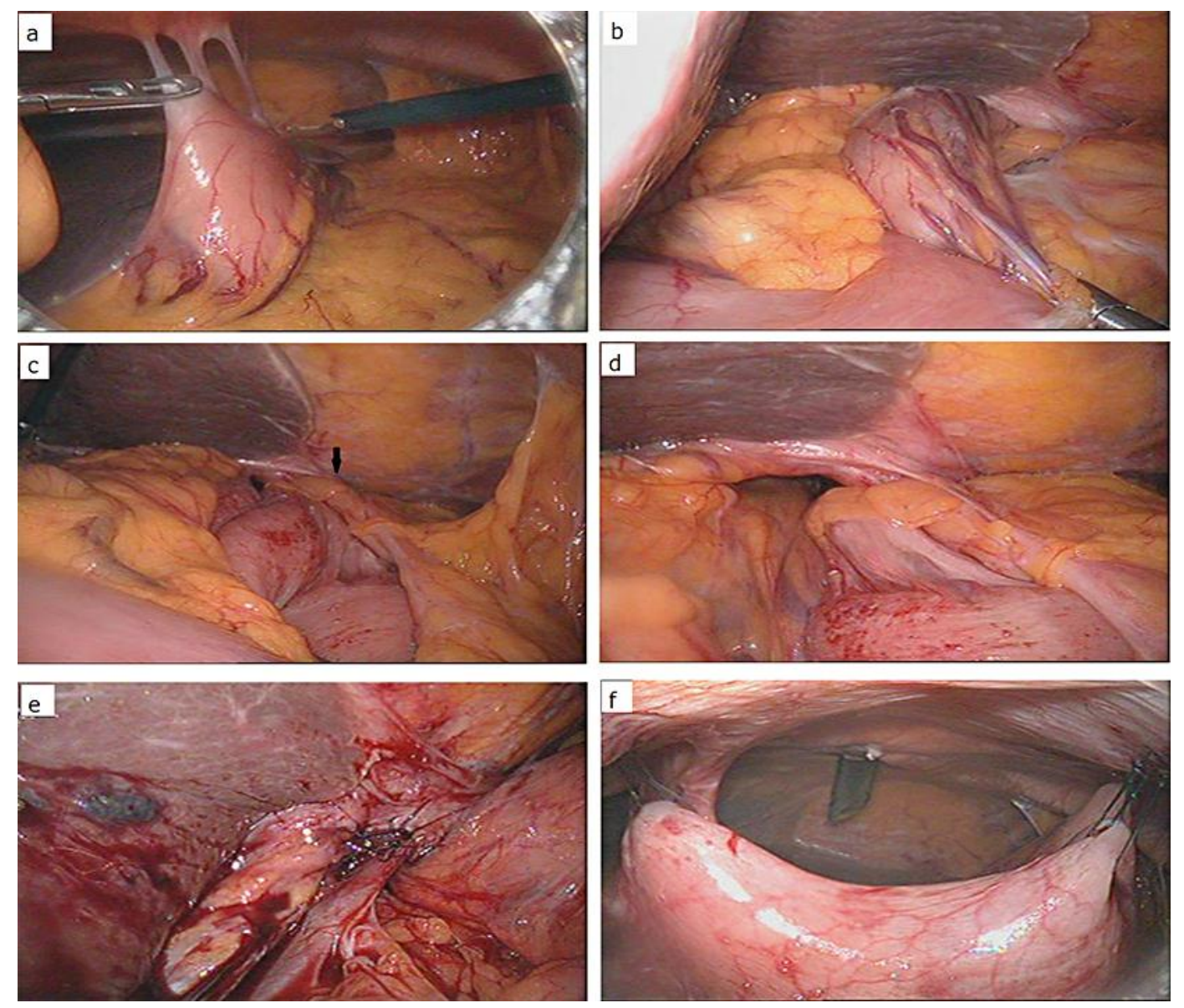

Fig. 3. Intraoperative findings. a The anterior stomach wall was adhered to the abdominal wall in three places from the antrum to the lower corpus of the stomach. $\mathbf{b}$ The upper corpus of the stomach was rotated and herniated into the esophageal hiatus. c The omentum (arrow) was adhered to the esophageal hiatus. d A $4 \times 3 \mathrm{~cm}$ hiatal hernia was opened. e The crura were closed by a primary suture. $\mathbf{f}$ The anterior stomach wall was fixed in three places to the abdominal wall from the upper corpus to the antrum. 